\title{
FLUXO DE CAIXA: FERRAMENTA INDISPENSÁVEL DE APOIO A GESTÃO DO CAPITAL DE GIRO
}

\author{
Evandro Morales dos Santos, Irene Caires da Silva
}

Universidade do Oeste Paulista - UNOESTE, Especialização em MBA em Finanças e Controladoria, Presidente Prudente, SP. E-mail: morales_evandro@hotmail.com, irene@unoeste.br.

\section{RESUMO}

O presente artigo tem por objetivo mostrar o fluxo de caixa como uma ferramenta indispensável de apoio a gestão do capital de giro em micro e pequenas, dentro do mercado competitivo em que estão inseridas. A falta de conhecimento contábil por parte dos gestores das micro e pequenas empresas favorece a má administração financeira do capital de giro, que, muitas vezes, acaba desencadeando um processo de declínio econômico e financeiro das empresas, proporcionando situações que desfavorecem o crescimento mercadológico e econômico dessas organizações. O presente artigo tem como metodologia um estudo bibliográfico de abordagem qualitativa. Atualmente, muitas empresas buscam uma ferramenta que possa auxiliar seus gestores no planejamento, controle e na tomada de decisão de maneira mais eficiente. Nesse sentido, a demonstração dos fluxos de caixa apresenta-se como instrumento capaz de suprir essa necessidade. Entretanto, sua utilização ainda é pouco praticada pelas micro e pequenas empresas, no que tange a sua administração financeira, podendo levar a sua descontinuidade. $O$ que nos traz a seguinte questão: Como o fluxo de caixa pode contribuir na gestão do capital de giro de uma empresa? Sendo assim, o presente artigo tem sua relevância no sentido de contribuir com o apoio à administração de micro e pequenas empresas, uma vez que essas compõem a maior parte do mercado empresarial do país, mas que por falta de conhecimento de gestão financeira, não conseguem dar continuidade às suas atividades, chegando à mortalidade em apenas dois anos de existência.

Palavra-Chave: Fluxo da Caixa. Capital de Giro. Micro e Pequenas Empresas. Tomada de Decisão.

\section{CASH FLOW: INDISPENSABLE TOOL TO SUPPORT THE MANAGEMENT OF GOLD CAPITAL}

\begin{abstract}
This article aims to show cash flow as an indispensable tool to support the management of working capital in micro and small, within the competitive market in which they are inserted. The lack of accounting knowledge on the part of the managers of micro and small companies favors the bad financial management of working capital, which often ends up triggering a process of economic and financial decline of the companies, providing situations that undermine the economic and economic growth organizations. The present article has as methodology a bibliographic study of qualitative approach. Many companies are now looking for a tool that can assist their managers in planning, controlling, and making decisions more efficiently. In this sense, the cash flow statement presents itself as an instrument capable of meeting this need. However, its use is still little practiced by micro
\end{abstract}


and small companies, in what concerns their financial management, and may lead to their discontinuity. Which brings us the following question: How can cash flow contribute to the management of a company's working capital? Therefore, the present article has its relevance in contributing to the support to the administration of micro and small enterprises, since these make up the majority of the country's business market, but lack of knowledge of financial management, can not to continue its activities, reaching mortality in just two years of existence

Keyword: Cash Flow. Working capital. Micro and Small Business. Decision Making.

\section{INTRODUÇÃO}

Entende-se que, toda empresa necessita de recursos financeiros para pôr em prática suas atividades fins. As operações de produção ou de vendas exigem do empreendimento uma quantidade disponível de dinheiro, capaz de suprir os gastos necessários à sua realização. Entretanto, a geração dos saldos de caixa está intimamente relacionada com os prazos ligados à gestão do capital de giro, que, por sua vez, são estabelecidos por meio de ciclos: operacional, econômico e financeiro.

Nesse contexto, a gestão do capital de giro necessita de uma atenção especial do administrador, pois, a cada ciclo realizado, o valor dos recursos aplicados sofrem transformações até retornarem à empresa em forma de lucro.

Compreender essa circulação dos disponíveis dentro da empresa requer, de seus gestores, uma ferramenta que Ihes possibilitem identificar informações reais e/ou projetadas, viabilizando o melhor caminho para manutenção desse capital.

Nesse sentido, o fluxo de caixa apresenta-se como uma ferramenta eficiente na gestão do capital de giro, por ser de fácil entendimento, possuindo uma estrutura dinâmica e flexível. Além disso, demonstra o uso dos recursos financeiros e, também, o saldo contido em caixa por atividades, possibilitando assim, à empresa o equilíbrio financeiro entre a liquidez e a rentabilidade.

Assim, o fluxo de caixa pode e deve ser usado como peça fundamental na administração financeira. Por meio desse, é possível identificar as entradas e saídas dos disponíveis de caixa, além de contribuir com a integralização de todas as áreas da organização.

Portanto, cabe à administração financeira tornar o uso dessa ferramenta contábil continuo e constante em prol de seu crescimento econômico e de seu desenvolvimento financeiro. Nesse sentido, o presente trabalho tem por tema o fluxo de caixa utilizado como ferramenta de apoio a gestão do capital de giro às micro e pequenas empresas.

O presente artigo tem como objetivo principal estudar o fluxo de caixa como ferramenta decisória na manutenção do capital de giro.

\section{METODOLOGIA}

Para que uma pesquisa científica seja configurada como tal e atinja seus objetivos aos quais se propôs a realizar, torna-se imprescindível definir sua metodologia, inclusive elucidar de maneira coerente e organizada, seus métodos, procedimentos e técnicas de pesquisa utilizadas no decorrer do trabalho. 
Assim, para a realização desta pesquisa foi utilizada a pesquisa qualitativa, que para Fachin (2005), este tipo de pesquisa é caracterizada por elementos descritos de forma analítica, sem a utilização de métodos de medição.

Em conjunto com a abordagem qualitativa, foi realizada uma pesquisa descritiva, na qual "[...] os fatos são observados, registrados, analisados, classificados e interpretados, sem que o pesquisador interfira neles" (ANDRADE, 2010, p. 112).

Os dados coletados para a realização dessa pesquisa advêm de fontes secundárias. Portanto, com relação às fontes de dados secundários, essa pesquisa se baseará na pesquisa bibliográfica que para Cervo e Bervian (2002) constitui-se geralmente no primeiro passo de qualquer pesquisa, tendo ela o intuito de reunir informações e conhecimentos de um problema que se busca resposta.

\section{RESULTADOS}

Em sentido estrito, o fluxo de caixa é a entrada e saída de dinheiro dentro de uma empresa em um determinado período de tempo. Contudo, a definição de fluxo de caixa vai além das entradas e saídas de dinheiro, pois, compreende as movimentações básicas dos recursos utilizados pela empresa para desenvolver suas atividades. Assim, de acordo com Padoveze (2005), o fluxo financeiro ou de caixa é o conjunto de movimentações financeiras decorrente do pagamento e recebimento dos eventos econômicos das operações da empresa, e das atividades de captação de recursos e investimentos de capital.

As empresas em seus processos normais e na perspectiva de dar continuidade as suas atividades, colocam-se profundamente na busca por um bom resultado econômico, ou seja, o maior lucro possível. Deixando muitas vezes de lado o controle de entradas e saídas de seus recursos.

O fluxo de caixa, além de mostrar as movimentações do caixa e equivalentes de caixa, pode e deve ser uma ferramenta de apoio à administração financeira destacando-se como um diferencial para a empresa dentro do mercado competitivo, podendo assim, assumir um papel em nível tático ou estratégico na administração dos recursos disponíveis.

Para Frezatti (1997, p.25), a abordagem tática "é aquela que referencia o fluxo de caixa como um instrumento de utilidade restrita e acompanhamento". O fluxo de caixa passa a ser um cumpridor de determinações mais amplas, ou seja, através dele os gestores tomam conhecimento da situação do caixa e analisam alternativas para administrar os seus recursos financeiros, postergando pagamentos ou antecipando entradas, viabilizando decisões táticas.

Ainda o mesmo autor, expõe que a abordagem estratégica "é aquela que afeta o nível de negócios da empresa não só em curto prazo, mas também, e principalmente, em longo prazo. Tem efeito sobre as decisões realmente estratégicas da empresa".

O uso do fluxo de caixa como ferramenta de gestão financeira, não é exclusividade das empresas de grande porte ou de empresas que destinam suas atividades para a obtenção de lucro.

Por ser uma ferramenta de fácil entendimento, seu uso expande-se a qualquer tipo de empreendimento, mesmo aqueles voltados a serviços sociais ou governamentais, pois, o caixa é um elemento pertinente em qualquer tipo de organização ou entidade, e que, precisa ser monitorado, a fim de se alcançar os objetivos propostos por cada tipo de organização (SILVA, 2010). 
Para Frezatti (1997, p.14), "a gestão do fluxo de caixa não se constitui em preocupação exclusiva das grandes empresas, ou mesmo daquelas voltadas para obtenção de lucro, mas das organizações em geral".

Outra visão sobre o fluxo de caixa é a dinâmica que ele pode proporcionar aos seus usuários. Uma empresa hoje, precisa se valer de instrumentos que Ihe tragam o máximo possível de informações claras, confiáveis, e de fácil entendimento.

Nesse sentido, o fluxo de caixa pode ser utilizado como meio de comparação e de análise das variações ocorridas no caixa, o que facilita um detalhamento das movimentações dos recursos (disponíveis). Tais comparações e análises se devem a sua composição estrutural, que the permite usar o passado como fonte de fatos realizados e projetar os possíveis resultados futuros (SILVA, 2010).

Para os analistas, o fluxo de caixa é o instrumento que lhes propiciam identificar o processo de circulação de dinheiro e equivalentes, através da variação do caixa, possuindo, segundo Silva (2010), três grandes dimensões de compreensão: a) o fluxo de caixa passado, isto é aquele que já foi realizado; b) o fluxo de caixa previsto, ou seja, previsão de caixa, que se refere a um período futuro; c) uma terceira forma que considera o passado e faz uma espécie de ajuste de certos usos futuros obrigatórios de recursos que ocorrerão no exercício seguinte.

A gestão do fluxo de caixa não é exclusividade apenas do setor financeiro, pois, as informações geradas por esta ferramenta dependem da gestão de outras áreas da empresa. Por exemplo, quando o setor de compra resolve aumentar o estoque de matéria-prima à vista, efetivamente sua decisão vai influenciar nos saldos dos disponíveis da empresa. De certa forma, a administração de maneira direta ou indireta envolve toda organização.

Assim, Matarazzo (2010), expõe que, o fluxo de caixa de uma empresa não depende exclusivamente do administrador financeiro, pois sua elaboração depende das decisões tomadas nas outras áreas da empresa como, por exemplo, nível de estocagem, prazos obtidos de fornecedores, expansão, estabilização ou redução do volume de atividades (produção e vendas), investimento no ativo permanente, dentre outros. A elaboração da estrutura do fluxo de caixa depende de três atividades básicas: atividade operacional, atividade de investimento e atividade de financiamento.

\section{DISCUSSÃO}

Percebe-se que ao longo dos conceitos expostos pelos autores, o fluxo de caixa é demonstrado pelas entradas e saídas de recursos disponíveis, movimentados pela empresa no decurso de suas atividades e que pode ser compreendido como um instrumento de grande relevância na vida financeira de qualquer empresa, servindo de subsídio para tomada de decisão por parte dos gestores e dos administradores.

Entretanto, para que uma empresa implante ou programe o fluxo de caixa como ferramenta de apoio a gestão financeira é preciso que haja a integração de toda organização, visto que, as decisões tomadas pelas outras áreas da empresa poderão influenciar na movimentação dos recursos que compõem o fluxo de caixa (SILVA, 2010; MATARAZZO, 2010).

Por exemplo, o setor de compra faz uma aquisição de matéria-prima à vista isso acarretará em um decréscimo no caixa da empresa, ou, se o setor de venda resolve estender os prazos de pagamentos para cliente, também causará uma retração no saldo projetado das entradas de recursos. Se ambas as decisões não foram projetadas ou até mesmo 
analisadas, poderão trazer para a empresa problemas de liquidez e comprometimento em sua situação financeira.

A empresa que utiliza o fluxo de caixa para a elaboração do planejamento financeiro encontra menores dificuldades, porque no início de cada período o gestor já vai saber suas dificuldades financeiras, e poderá antecipadamente tomar decisões fundamentadas (FREZATTI, 1997).

Com a utilização do fluxo de caixa, a empresa poderá organizar-se e planejar o futuro, ajustando seus orçamentos na medida em que os períodos forem acontecendo. Também poderá ordenar as informações referentes a pagamentos e recebimentos, podendo assim negociar descontos e maiores prazos com seus fornecedores (SILVA, 2010).

Existem formas diferentes de apresentar o fluxo de caixa. Deste modo, cada empresa deverá utilizar aquele que se adapta mais a sua realidade, pois cada um leva em conta as movimentações de caixa conforme as características de cada empresa.

Em linhas gerais, toda empresa deve ter um de fluxo de caixa, sendo ela de grande porte ou não, pois por meio dele o gestor pode fazer todo o planejamento necessário para o bom andamento da empresa. Por meio do fluxo de caixa a empresa poderá desenvolver estratégias que possibilitem obter resultados adequados para alcançar os objetivos planejados.

\section{CONCLUSÃO}

Com o desenvolvimento deste artigo, o objetivo foi atingido satisfatoriamente, destacando-se o papel fundamental e primordial dos fluxos de caixa como peça integrante do planejamento financeiro das micro e pequenas empresas, auxiliando no controle das entradas e saídas de disponíveis (capital de giro) destas, durante o seu processo operacional.

Além de subsidiar os gestores na tomada de decisão, conduzindo a administração do empreendimento a um bom desempenho econômico-financeiro.

Entretanto, sabe-se que é um instrumento pouco utilizado pelas micro e pequenas empresas, fato decorrente da não obrigatoriedade legal ou simplesmente pelo desconhecimento técnico da área por parte de seus administradores ou proprietários.

Por meio da elaboração dos fluxos de caixa, são fornecidas informações referentes a recebimentos e pagamentos gerados pela empresa em um determinado período, a capacidade da empresa de honrar seus compromissos, a atividade que mais contribuiu para a geração do lucro e a real posição financeira da empresa. Além de fornecer os valores relacionados a entradas e saídas de dinheiro ou equivalentes, o fluxo de caixa pode ser utilizado como instrumento de projeções futuras, viabilizando comparações entre resultados projetados e o realizado. Permitindo uma avaliação quanto ao desempenho da gestão do caixa, identificando saldos positivos ou negativos.

Em relação a gestão do capital de giro, percebeu-se que esta ferramenta possibilita uma melhor visualização e controle do capital que circula nas atividades operacionais da empresa.

Ao concluirmos este artigo, fica evidente que não esgotamos o assunto acerca do uso das ferramentas contábeis em prol da administração financeira das micro e pequenas empresas, pelo contrário, esperamos ter contribuído para que mais pessoas desenvolvam pesquisas que estimulem essas empresas a entenderem o papel do fluxo de caixa em prol de seu crescimento mercadológico e econômico-financeiro, utilizando-a em seu cotidiano, facilitando, por tanto, o processo de tomada de decisão por seus gestores. 


\section{REFERÊNCIAS}

ANDRADE, M. M. Introdução à metodologia do trabalho científico: elaboração de trabalhos na graduação. 10. ed. São Paulo: Atlas, 2010.

CERVO, A.L.; BERVIAN, P.A. Metodologia científica. 5. ed. São Paulo: Prentice Hall, 2002.

FACHIN, O. Ferramentas de Metodologia. 5. ed. São Paulo: Saraiva 2005.

FREZATTI, F. Gestão do fluxo de caixa diário: como dispor de um instrumento fundamental para o gerenciamento do negócio. São Paulo: Atlas, 1997.

MATARAZZO, D.C. Análise financeira de balanços: abordagem gerencial. 7. ed. São Paulo: Atlas, 2010.

PADOVEZE, C.L. Introdução à administração financeira: texto e exercícios. São Paulo: Pioneira Thomson Learning, 2005.

SILVA, J.P. Análise financeira das empresas. 10. ed. São Paulo: Atlas, 2010. 